\title{
El grupo rítmico y el grupo fónico en la clase de ELE
}

\author{
Silvia Planas Morales \\ Universitat Rovira i Virgili \\ silvia.planas@urv.cat
}

Resumen: En este artículo se expone la aplicación de la jerarquía fónica (Cantero, 2002) en la didáctica de la pronunciación, argumentando a favor del grupo rítmico y del grupo fónico como agrupaciones de palabras en torno a un acento — paradigmático y sintagmático, respectivamente- que facilitan la adquisición del ritmo del español, con lo cual el alumno de ELE adquiere mayor fluidez en el discurso oral y mejor comprensión auditiva.

Palabras claveः grupo rítmico, grupo fónico, acento paradigmático, acento sintagmático, pronunciación ELE.

Abstract: This article describes the application of phonetic hierarchy (Cantero, 2002) to the didactics of pronunciation, advocating for rhythm and phonic groups as clusters of sounds and words around a stress -paradigmatic and syntagmatic, respectively - which favors the acquisition of the rhythm of Spanish, which helps the student to be more fluent and obtain a better listening compehension.

Key words: rhythm group, phonic group, paradigmatic stress, syntagmatic stress, pronunciation of Spanish as a Foreign Language. 


\section{Introducción}

El ritmo de una lengua se define como «la sensación perceptiva producida por la percepción de ciertos elementos, acentos, sílabas, etc., a intervalos regulares de tiempo» (Gil, 2007: 324). Si consideramos solo el acento y la sílaba, tenemos los dos grandes grupos en que dividen tradicionalmente las lenguas en función del ritmo: (a) las lenguas acentualmente acompasadas y (b) las lenguas silábicamente acompasadas.

En las lenguas acentualmente acompasadas, el acento prosódico es el elemento que tiende a aparecer en intervalos regulares de tiempo (isocronía acentual). Es decir, el acento es el que marca el compás sin tener en cuenta el número de sílabas átonas que el hablante pronuncie entre dos sílabas tónicas. En este grupo se clasifican lenguas como el inglés, el alemán o el portugués de Brasil.

Las lenguas silábicamente acompasadas son aquellas en las que las sílabas tienden a presentar la misma duración (isocronía silábica). La sílaba es el elemento que marca el compás, lo que quiere decir que las fronteras entre sílabas tienden a aparecer en intérvalos regulares de tiempo y que, por lo tanto, lo que tarde un hablante en pronunciar un enunciado dependerá del número de sílabas que contenga. Se clasifican en este grupo el español, el catalán, el francés y el italiano.

En ambas clasificaciones se habla de tendencia porque, como todas las clasificaciones lingüísticas excluyentes, esta división no deja de estar exenta de discusión en cuando una lengua clasificada en un grupo presenta características del otro grupo. Por este motivo, estudiosos del tema señalan que el ritmo no solo depende de la tendencia a la temporalización acentual o silábica de una lengua, sino que también depende de la complejidad de su estructura silábica, de la posición habitual del acento en la palabra léxica y de cualquier otro elemento que repercuta en el eje temporal en que se divide un enunciado (Lahoz, 2012: 104-5).

Sobre si el tipo de sílaba repercute en la sensación del ritmo, Delattre y Olsen (1969: 169) dicen lo siguiente:

El hecho de que las sílabas francesas y españolas sean menos complejas que las inglesas o alemanas es quizá una de las razones por las que las lenguas románicas suenan más repetitivas, más monótonas que las lenguas germánicas. Por otro lado, la preferencia del alemán y del inglés por una sílaba ligeramente más larga con cierre consonántico produce una impresión más pesada, más entrecortada y contenida. La tendencia del español y del francés a una sílaba más corta con cierre vocálico resalta su cualidad ligera, sonora y fluida.

La posición habitual del acento en la palabra respecto a su repercusión en el ritmo tiene que ver con el pie acentual, el cual puede estar formado por una sílaba 
tónica (final yámbico), una sílaba tónica y una sílaba átona (final trocaico) o por una sílaba tónica y dos sílabas átonas (final dactílico). Para Gili Gaya (1955)², el ritmo idiomático del español se debe en gran parte a su tendencia a los finales trocaicos $\left({ }^{6}-\right.$ ).

Sobre la dependencia del ritmo por otro elemento que repercuta en el eje temporal, autores como Toledo (1988), Murillo y Alcoba (1999) o Cantero (2002) no consideran la sílaba ni el pie acentual como los elementos que marcan el ritmo del español, sino que consideran que el elemento que marca la periodicidad es el grupo rítmico o tónico, formado por una sílaba tónica y una o más sílabas átonas, y que se diferencia del pie acentual en que siempre se trata de una unidad con sentido o significado.

Nadie pone en tela de juicio que el ritmo sea muy importante porque es el compás de una lengua, imprescindible para hacerla inteligible. Es curioso, sin embargo, que en el inventario de Pronunciación y prosodia del Plan Curricular del Instituto Cervantes (PCIC), no se haga una mención al grupo rítmico en el apartado 4. El ritmo, las pausas y el tiempo, que se divide en la percepción y producción del ritmo (subapartado 4.1.) y en la percepción y producción de las pausas y el grupo fónico (subapartado 4.2.). En la percepción y producción del ritmo, el PCIC tiene en cuenta solamente aspectos de la sílaba y del pie acentual del español. En la percepción y producción de las pausas y el grupo fónico, se refiere al ritmo como el tempo de los grupos fónicos - a los cuales trata como estructuras sintácticas e informativas que se pronuncian entre pausas-, porque la extensión media habitual de 8 sílabas es la que se considera que marca el ritmo o tempo andante característico del español.

El objetivo de este artículo es adentrar al profesor de ELE con poca formación en fonética, en la jerarquía fónica (Cantero, 2002), del grupo rítmico al grupo fónico, que explica la prosodia del español y con la cual podrá afrontar las dificultades que supone enseñar el ritmo de la lengua.

\section{El grupo rítmico y el acento paradigmático}

En el enunciado Ellas comerán el pescado por la noche hay siete palabras léxicas (ellas, comerán, el, pescado, por, la, noche), pero solo cuatro grupos rítmicos: [éllas], [komerán], [elpeskádo] y [porlanóche]. Los dos primeros grupos rítmicos son palabras fónicas constituidas por una palabra tónica (ellas y comerán), mientras que los dos últimos grupos rítmicos son palabras fónicas compuestas por una

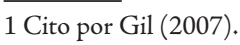


palabra átona y una palabra tónica, la primera (el pescado), y dos palabras átonas y una palabra tónica, la segunda (por la noche).

La diferencia, por tanto, entre palabra léxica y palabra fónica es que la palabra fónica puede estar constituida por más de una palabra léxica, pero solo puede poseer una vocal tónica, que es aquella en la que recae el acento paradigmático de la palabra léxica y alrededor de la cual los sonidos se agrupan para percibirse en bloque (Cantero, 2002: 56). Es decir, no percibimos los fonemas de uno en uno, aunque sí distinguimos fonológicamente cada uno de ellos, ni percibimos el acento prosódico por separado, aunque sí distinguimos la vocal tónica frente a las vocales átonas.

Por el paradigma acentual del español, las palabras pueden ser oxítonas (café, ir, estrangulador), paroxítonas (chocolate, fácil, piano) y proparoxítonas (brújula, estúpido, capítulo). Las palabras españolas consideradas superproparoxítonas o sobreesdrújulas, en realidad, son palabras fónicas compuestas por una forma verbal y dos pronombres clíticos pospuestos, que la escritura ya se ha encargado de juntar visualmente porque en el habla forman un grupo rítmico (cuénteselo = cuénte + se + lo [kuénteselo]), aunque no haya hecho lo mismo cuando los clíticos se anteponen al verbo (se lo cuente [selokuéñnte]). Sin embargo tanto cuénteselo como se lo cuente son palabras fónicas que se constituyen alrededor de un acento. Lo mismo podemos decir sobre considerar palabras llanas y esdrújulas, respectivamente, a las palabras fónicas compuestas por el verbo y uno o dos clíticos antepuestos, (dame, póntelo), por el simple hecho de que se escriben juntas.

\subsection{Los enlaces de palabras y el resilabeo}

La pronunciación de más de una palabra en la palabra fónica facilita los enlaces y el consiguiente resilabeo, que también se hace extensible al grupo fónico, porque en el español hablado las palabras se enlazan, produciéndose cambios en la distribución original de las sílabas y, en algunos casos, reduciéndose el número total: con ambición > co.nam.bi.ción, la_araña > la.ra.ña $(1+3>3$ sílabas).

Pero ello no quiere decir que el resilabeo en español no esté sujeto a ciertas reglas o que no haya ciertas restricciones fonéticas. El resilabeo se produce en español solo si entre las palabras que se enlazan se producen las siguientes situaciones (Hualde, 2005; Quilis, 2002; Gil, 2007, Rico, 2012):

- Contracción silábica por enlace de vocales entre límites de palabras:

- Reducción a una sola vocal: una animalada (u.na.ni.ma.la.da)

- Formación de diptongo: la imaginación (lai.ma.gi.na.ción)

- Formación de triptongo: Imperio inglés (im.pe.rioin.glés). 
Excepción: Cuando el resultado puede provocar ambigüedad: la asimetría vs. la simetría.

- Resilabeo consonante-vocal entre límites de palabras, siempre y cuando la palabra termine en consonante y la siguiente empieza por vocal o por diptongo decreciente, pero no por diptongo creciente: el oso (e.lo.so), con autoridad (co.nau.to.ri.dad), quieren buevos (quie.ren.ue.vos).

- Contracción silábica por enlace de consonantes iguales: ciudad dormitorio (ciu.da.dor.mitorio).

En el resilabeo se debe tener en cuenta que cuando una palabra terminada en $-r$ se enlaza con otra que empieza en vocal, el resultado es la rótica percusiva [ $[$ ] (color_esmeralda > co.lo.res.me.ral.da), mientras que si se enlaza con una palabra que empieza por $r$-, el resultado es la rótica vibrante [r] (color_rojo > co.lo.rro.jo).

Otro caso especial es la conjunción $y$, pues, aunque siempre forme palabra fónica con la tónica posterior, cuando se encuentra entre vocal y consonante en el grupo fónico, se enlaza con la vocal formando un diptongo (ciencia $y \_a r t e>c i e n$. cias.iar.te; oro_y plata > o.roi.pla.ta).

\subsection{El grupo rítmico en la clase de ELE}

El PCIC no hace mención ni del grupo rítmico ni de la palabra fónica en los inventarios de pronunciación, pero sí dedica un apartado entero a la sílaba y el acento (apartado 3), y el proceso del resilabeo lo trata en el apartado de fonemas (apartado 5). Del mismo modo, en manuales sobre pronunciación del español, podemos encontrar capítulos dedicados a la sílaba y al acento, así como ejercicios de enlace de palabras y resilabeo en los capítulos dedicados a las vocales y a las consonantes, pero solo como un fenómeno de unión de vocales, de consonantes y de consonantes con vocales que se produce en el habla. Sin embargo, el reconocimiento y la práctica de los grupos rítmicos resulta esencial para que el alumno adquiera el ritmo del español. Por este motivo es aconsejable que el profesor de ELE dedique tiempo a este cometido. Para explicar a los alumnos lo que es la palabra fónica, la siguiente definición funciona muy bien:

Cuando hablamos español, pronunciamos palabras como si fueran una sola. Esto es lo que llamamos palabra fónica. La palabra fónica está formada por una o más palabras átonas y una palabra tónica. Las palabras átonas no poseen acento, por este motivo se enlazan con una palabra que sí lo tiene.

Aunque se explique al alumno que las palabra átonas son aquellas que solo tienen función gramatical, como el número de tipo de palabras es muy reducido y 
su frecuencia de aparición es muy alta, es aconsejable que el profesor facilite una relación de palabras átonas, sirviéndose de listados como el siguiente:

- Artículos determinados: el, la, los, las

el bolígrafo, la libreta, los libros, las carpetas

- Pronombre clíticos: me, te, se, nos, os, le, les, la, las, lo, los cántala, me miró, os lo dije, nos veremos, le permití, las saludé, se les advirtió, diviértete, dáselos

+ Posesivos antepuestos: mi, mis, tu, tus, su, sus. mi gato, mis gafas, tu tía, tus elogios, su preferido, sus manías

- Preposiciones: a, ante, bajo, con, contra, de, desde, en, entre, hacia, hasta, para, por, sin, sobre, tras. (Exceptoः según).

a Roma, con mi amiga, de acuerdo, en el campo, sin duda, para Elisa, por supuesto, ante todo, desde aquí, bajo llave

+ Conjunciones: y, e, o, u, ni (coordinación), que (subordinación), si (condicional)...

\section{Estudia inglés y alemán}

Viene dos o tres veces por semana

Por una u otra vía, lo conseguiremos

No le gusta ni la física ni la química

Quiero que vengas

Si estudias, aprobarás.

No es necesario explicar a los alumnos (a menos que sean universitarios que estén cursando estudios de lengua española) que una palabra tónica ya de por sí es una palabra fónica, ni hablarles del acento paradigmático.

La comparación de los clíticos pospuestos con los antepuestos al verbo son el mejor ejemplo para que los alumnos entiendan el concepto de palabra fónica. A los alumnos de lenguas que no tienen el artículo determinado, como es el caso de los alumnos chinos o japoneses, se les puede explicar que la agrupación del artículo con el nombre equivale a una sola palabra, como en su lengua. Además, la práctica de la pronunciación de estas palabras fónicas facilita la memorización de la concordancia en género y número, lo cual también es provechoso para los alumnos con lenguas cuyo artículo es invariante y para los que en su lengua el género de un nombre no coincide con el del español.

La pronunciación de series de números, de los días de la semana (con o sin artículo determinado) y de los meses del año, repercute positivamente en la percepción del ritmo, y más aún si se realiza con una cierta cantinela. 
Para la percepción de la vocal tónica es muy eficaz marcarla con la duración, pues aunque se diga que el acento en español es de intensidad, cabe recordar que es la combinación del tono fundamental (F0) con la intensidad o con la duración, - y no el hecho de forzar las cuerdas vocales - lo que lo caracteriza acústicamente.

Es importante que el alumno perciba el ritmo desde el nivel inicial, para ir entendiéndolo y afianzándolo a lo largo de su aprendizaje.

\section{El grupo fónico y el acento sintagmático}

El grupo fónico es el nivel inmediatamente superior al grupo rítmico, pues está constituido por una serie de palabras fónicas organizadas alrededor de un acento sintagmático (Cantero 2002: 77). El acento sintagmático se imprimer en la última vocal tónica del grupo, aumentando su duración y añadiéndole inflexión tonal, ya sea para mantener la línea entonativa del enunciado (grupo fónico interno) o para distinguir modalidades oracionales (grupo fónico final). ${ }^{2}$

El acento sintagmático no actúa a nivel léxico, sino sintáctico — por este motivo también se le conoce como acento de frase (sentence phrases) o de núcleo entonativo-. En la oración la mayor cata vino con queso, hay cuatro grupos rítmicos: [lamayór], [cáta], [víno] y [conquéso]. Pero la organización de las palabras fónicas en dos grupos fónicos varía según dónde el hablante haga recaer el primer acento sintagmático. Además, en esta frase escrita en la cual [cáta] tanto puede ser nombre como forma verbal, solo el acento sintagmático puede distinguir el significado de los dos posibles significados del mensaje: ${ }^{3}$

(1) [lamayÓr] [cátavínoconquÉso]

(2) [lamayórcÁta] [vínoconquÉso]

En el enunciado (1), el primer acento sintagmático recae en la vocal tónica de mayor, haciendo que el sujeto sea La mayor y el predicado, cata vino con queso. En el enunciado (2), el primer acento sintagmático recae en la vocal tónica de cata, con lo cual el hablante estaría indicando que esta palabra es el núcleo del sujeto y que el verbo de la oración es la forma vino del verbo venir.

Además de como unidad prosódica, el grupo fónico se suele definir como una unidad sintáctica y una unidad con sentido (cf. Iribarren, 2005). Identificarla con la unidad sintáctica puede parecer lo más fácil para enseñar lo que es un grupo fónico, porque el alumno de ELE está familiarizado con el sintagma y su función

2 Sobre la aplicación didáctica del acento sintagmático en la pronunciación, véase Planas Morales (en prensa). 3 Para indicar que cuál es la vocal tónica en la que recae el acento sintagmático, la transcribimos en mayúscula. 
(Sujeto, Verbo, OD, OI y CC) por los ejercicios de gramática y de comprensión escrita - es decir, de comprensión del orden de la palabras en la oración (Villalba, 2010) - y porque los grupos fónicos son fácilmente identificables en los textos que se utilizan para practicar la lectura en voz alta. Sin embargo, aunque para pronunciar correctamente un sintagma se deban seguir las reglas del grupo fónico, un grupo fónico no siempre coincide con un sintagma. Por ejemplo, con la oración Me gustan las películas de terror, se pueden emitir tres enunciados perfectamente inteligibles a oídos del receptor, y sin variar el significado del mensaje:

(3) [megÚstan] [laspelículasdeterrÓr]

(4) [megústanlaspelÍculas] [deterrÓr]

(5) [megÚstan] [laspelÍculas] [deterrÓr]

(6) *[megÚstanlas] [películasde] [terrÓr]

En el enunciado (3), el sujeto de la oración se agrupa en un único grupo fónico (las películas de terror). En el enunciado (4), el núcleo del sujeto (las películas) se separa de su complemento para formar parte del primer grupo fónico con los elementos sintácticos del predicado (me gustan las películas), recayendo el acento sintagmático en la vocal tónica de películas. En el enunciado (5) los tres grupos fónicos coinciden con los grupos rítmicos, con lo cual el hablante disminuye su velocidad de elocución, pero el significado del mensaje es el mismo que en (3) y (4). Sin embargo, en el enunciado (6), a pesar de que los tres grupos fónicos también coincidan con tres grupos rítmicos, perceptiblemente, la oración no es claramente inteligible porque algunos elementos de los grupos fónicos no mantienen una relación gramatical (me gustan las y películas de no tienen sentido).

Como podemos ver por los enunciados de (3), (4) y (5), la extensión de los grupos fónicos es variable $y$, si no es que afecta al significado del mensaje, es el hablante quien decide cómo divide un enunciado en grupos fónicos.

La jerarquía fónica que se establece con el acento sintagmático no permite que se produzcan pausas dentro del grupo fónico, porque las palabras que lo forman se enlazan entre sí. Por este motivo, el resilabeo que se produce en la palabra fónica, entre las palabras átonas y tónicas, en el grupo fónico se extiende a los enlaces entre las palabras que lo componen:

(7) Estábamos al borde del abismo y hemos dado un paso al frente. ${ }^{4}$ [es.tá.ba.mo.sal.bÓr.de] [de.la.bÍs.mo] [ie.mos.da.doun.pÁ.so] [al.frÉn.te]

La definición más tradicional del grupo fónico se basa en las pausas, entendiendo que «el grupo fónico es la porción del discurso comprendida entre dos

4 Famosa frase pronunciada por Francisco Franco Bahamonte. 
pausas» (Quilis, 2002: 419). Sin embargo, esta definición crea confusión en el alumno porque identifica pausa con silencio y, además, no siempre una pausa ortográfica se corresponde con una pausa en pronunciación. Las pausas que son silencios son las que se producen cuando el hablante da por acabado su turno de palabra. En el caso que no haya terminado de decir todo lo que quería porque tiene dudas de cómo continuar, se producen lo que se denominan pausas llenas (eeehhh, mmmm). También son silencios las pausas intencionadas, las que utilizamos para captar la atención del oyente. ${ }^{5}$

Las pausas entre grupos fónicos internos, son pausas mínimas o virtuales, pero no son silencios, sino interrupciones en la emisión sonora del enunciado que se originan por motivos fisiológicos (la necesidad de respirar) o lingüísticos. Cuando se trata de motivos lingüísticos se habla de pausas lingüísticas, pues afectan el significado de la oración:

(8) No, es así.

$$
\text { [nÓ] \# [e.sa.síl }
$$

(9) No es así.

[noe.sa.sí]

En este aspecto, el profesor de ELE debe tener en cuenta que las pausas virtuales no siempre se corresponden con las comas ortográficas:

(10) No estaba de acuerdo y, por lo tanto, le dijo que no.

[noestabadeacuÉrdo] [yporlotÁnto] [le dije que nÓ.]

(11) Facil, fácil, no es, pero se puede hacer.

[facilfÁcil] [noÉs] [perosepuedeacÉr.]

\subsection{Sobre la desacentuación de las palabras tónicas y la acentuación de las palabras átonas.}

Se dice que hay palabras que se desacentúan cuando van agrupadas para formar compuestos, como es el caso del primer elemento de los numerales (treinta y tres), de los nombres propios compuestos (José Carlos) o cuando van seguidos por el apellido (Carlos Sánchez), así como los sustantivos que se vinculan a adverbios (escaleras abajo). Sin embargo, una palabra no puede desacentuarse, si consideramos que el acento paradigmático es inherente a la formación de la palabra léxica y no un elemento que se pueda «poner» $y$ «quitar». Por otro lado, si existiera un proceso de desacentuación, el verbo auxiliar de los tiempos verbales compuestos

5 Para una explicación más extensa sobre las pausas, vésase Gil (2007). 
(babia caído) o el primer elemento de las perífrasis verbales (va cayendo), por ejemplo, también deberían desacentuarse y no es así.

En realidad, no es necesario hablar de desacentuación cuando el acento sintagmático es el que determina cuál es el acento principal del grupo fónico, porque si el compuesto se pronuncia como un solo grupo fónico, el acento sintagmático siempre recae en el último elemento: [tréintaitrÉs], [josécÁrlos], [cárlosÁnchez], [escalérasabÁjo]. Y si forma parte de un grupo fónico, el último elemento del compuesto recibirá el acento sintagmático según la posición que ocupe: diga treinta y tres [dígatréintaitrÉs], treinta y tres animales [tréintaitrésanimÁles]. Además, ¿̇cómo se explica que haya palabras que se desacentúan, y, en cambio, los adverbios acabados en - mente tengan una doble acentuación?

También se dice que las palabras átonas dichas de manera aislada se pronuncian tónicas, pero esta acentuación no es porque se le añada el acento paradigmático, sino porque el acento sintagmático recae sobre ellas, ya que pronunciada individualmente una palabra átona es un grupo fónico $y$, como tal, posee acento sintagmático. Veamos unos ejemplos extraídos de una clase de ELE:

Profesor: ¿Cuál es el artículo de la palabra «hada»? ¿El o la? ([Él] [olÁ])

Alumno 1: La. ([1Á])

Alumno 2: El. ([Él])

Alumno 3: Los dos. ([los5dÓs])

Profesor: (iं $+\ldots ? !)$

Alumno 3: Como la palabra «estudiante».

Además, si diéramos por cierto que, en estos casos, el acento es el paradigmático, deberíamos tener dos entradas en el léxico para los artículos ejemplificados: una entrada para el artículo átono que acompaña al nombre y otra entrada para el artículo tónico que no acompaña al nombre.

\subsection{El grupo fónico en la clase de ELE}

El PCIC, en el subapartado 4.2.1 del inventario de pronunciación del nivel B1B2, da un listado de agrupaciones de palabras que el hablante de español suele pronunciar automáticamente como grupo fónico, y que el profesor de ELE debe tomar en consideración:

4.2.1 Agrupaciones que habitualmente no admiten pausas

El artículo y el nombre el niño

Un nombre y un adjetivo

plato sopero 
Un adjetivo y un nombre verde hojarasca

Un verbo y un adverbio duermo mal

Un adverbio y un verbo no estudia

Un verbo y un pronombre átono o clítico lo creo

Un adverbio y un adjetivo mal avenido

Un adverbio y otro adverbio bastante mal

Los componentes de las formas verbales compuestas babian cantado

Los componentes de las perífrasis verbales se echó a llorar

La preposición con su término con mi libro

Las denomina agrupaciones que habitualmente no admiten pausa porque son unidades que o bien son grupos rítmicos o bien la relación entre sus elementos especifica el significado conjunto de la agrupación (el adjetivo clasifica al nombre, el adverbio modifica al adjetivo, etc.). Ahora bien, la mayoría de estos ejemplos suelen estar integrados en una agrupación mayor de palabras porque el español tiende a construir unidades de entre 5 y 10 sílabas, siendo de 8 sílabas el grupo fónico más frecuente, pues, como decía Gili Gaya (1993), es el que caracteriza mejor su ritmo de tempo andante.

Pero, ¿cómo practicamos el grupo fónico en la clase de ELE, si su extensión es variable y en los grupos internos depende de la decisión del hablante cuando no hay un motivo lingüístico que pueda hacer que cambie el significado del mensaje?

Identificar el grupo fónico con el sintagma puede parecer, en principio, una buena solución; pero, como hemos visto en los ejemplos (3) y (4) (ver supra), el alumno de ELE no siempre va a oír esa correlación en español. Por este motivo, una explicación del grupo fónico como la siguiente da muy buenos resultados:

«En el español hablado no solo se unen las palabras átonas con las palabras tónicas, sino que también se pueden enlazar palabras tónicas y palabras fónicas. Esto es un grupo fónico. Cuando se pronuncian juntas más de una palabra tónica, siempre hay una sílaba tónica que es la que lleva el acento principal, es el acento sintagmático. El acento sintagmático recae en la última sílaba tónica del grupo fó- 
nico, y se destaca de las demás porque la pronunciamos aumentando su duración y dándole cierta inflexión tonal.» ${ }^{6}$

Lo mejor al principio es practicar con textos en los que el profesor haya delimitado de antemano los grupos fónicos, para que el alumno centre la atención en el acento sintagmático. El texto puede ser un poema como, por ejemplo, la Rima VI de Gustavo Adolfo Bécquer:

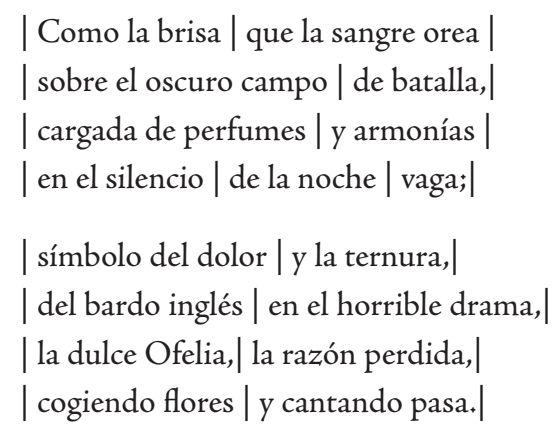

El ejercicio consiste en que los alumnos, antes de practicar la pronunciación resultante, reescriban el texto enlazando las palabras de cada grupo fónico teniendo en cuenta las redistribuciones silábicas que puedan darse y marcando el acento sintagmático:

[ comolabrÍsa] [quelasangreorÉa]
[sobreloscurocÁmpo] [debatÂlla],
[cargadadeperfÚmes] [iarmonÍas]
[enelsilÉncio] [delanÓche] [vÁga];
[símbolodeldolor] [ilaternura],
[delbardoinglÉs] [enelorribledrÁma],
[ladulceofÉlia], [larazónperdÍda],
[cogiendoflÓres] [icantandopÁsa].

\subsubsection{La comprensión auditiva}

La pronunciación en la clase de ELE no se limita a la emisión correcta de palabras, grupos fónicos y enunciados, sino que también se ocupa de que el alumno perciba correctamente la forma fonética del discurso oral, porque sin tal percepción no es posible una auténtica y completa comprensión auditiva del mensaje. Precisamente la parte de comprensión auditiva ha aumentado su valor en el peso

6 Para los alumnos chinos se puede añadir: «La sílaba que posee el acento sintagmático es, por tanto, la sílaba fuerte del grupo fónico»» 
de la nota de los exámenes del DELE, por lo que no se deben menos tener como actividades didácticas los dictados y la transcripción de audiciones.

Cuando se trata la comprensión auditiva, la importancia de la corrección de los dictados y de la transcripción de una audición no son las normas ortográficas, sino las normas del grupo fónico, porque de lo que se trata es que el alumno se dé cuenta de por qué ha oído lo que ha oído. Los alumnos suelen estar demasiado preocupados en oír palabras léxicas, y muchas veces escriben la palabra conocida que más se parece a lo que han oído, aunque no guarde relación ninguna. Realmente es sorprendente lo que los alumnos pueden llegar a oír cuando se les dicta un texto o tienen que transcribir una audición.

\section{Conclusiones}

La pronunciación y percepción del discurso se estructura jerárquicamente en unidades fónicas que no impiden identificar léxica, gramatical y semánticamente los elementos que lo componen. Estas unidades son los grupos rítmicos y los grupos fónicos (Cantero, 2002), cuya práctica en la clase de ELE facilita la adquisición del ritmo del español y agiliza el proceso de comprensión del discurso.

En español, la necesidad de enlazar las palabras átonas con las tónicas y la tendencia natural a marcar la última sílaba tónica del grupo fónico hace que una interrupción en el enlace de las palabras produzca una sensación perceptiva de interrupción del ritmo. Por este motivo, es importante que, para mantener el ritmo y la fluidez en la pronunciación del español, se tengan en cuenta los siguientes aspectos claves en la clase de ELE:

- Tanto las palabras que forman una palabra fónica como las que constituyen un grupo fónico se enlazan entre sí, con lo cual se pueden producir cambios en la distribución original de las sílabas y, también, reducirse el número total (mi_amiga > mia.mi.ga; mi_imaginación > mi.ma.gi.na. ción).

- No es preciso que un grupo fónico coincida con un sintagma, pero nunca se deben separar los elementos de una palabra fónica, que es el grupo rítmico básico.

- La extensión del grupo fónico es variable, pero lo importante para mantener la prosodia propia del español es el acento sintagmático, que recae en la última sílaba tónica del grupo fónico, aumentando su duración y dándole cierta inflexión tonal.

Por otra parte, no se debe descuidar la práctica de la comprensión auditiva, pues los alumnos no oirán las palabras pronunciadas aisladamente, sino agru- 
padas y enlazadas (resilabeo) en bloques fónicos, los cuales, además, no necesariamente coincidirán con una unidad sintáctica que identifique fácilmente su función gramatical.

\section{Referencias bibliográficas}

Alcoba, S. y Murillo, J. (1999): «Intonation in Spanish». En D. Hirst y A. di Cristo (eds.). Intonation Systems. A survey of Twenty Languages. Cambridge University Press: $152-166$.

Cantero, F.J. (2002): Teoría y análisis de la entonación. Barcelona. Publicacions de la Universitat de Barcelona.

- y Font-Rotchés, D. (2009): «Protocolo para el análisis melódico del habla». Estudios de Fonética Experimental, XVIII: 17-32.

Delattre, P. y Olsen, C. (1969): «Syllabic features and phonic impression in English, German, French and Spanish». Lingua 22: 160-175.

Escandell-Vidal, M.V. (1999): «Los enunciados interrogativos. Aspectos semánticos y pragmáticos», en Bosque, I. y Demonte, V. (eds.). Gramática Descriptiva de la Lengua Española. Madrid. Espasa, vol. 3, cap. 61:3929-3991.

GIL, J. (2007). Fonética para profesores de español: De la teoría a la práctica. Madrid. Arco / Libros.

Gili Gaya, S. (1955): «Introducción a los estudios ortológicos y métricos de Bello». En Paraíso, I. (ed.) (1993). Estudios sobre el ritmo. Madrid. Istmo: $115-157$.

Hualde, J.I. (2005). The Sounds of Spanish. Cambridge. Cambridge University Press.

Iribarren, M.C. (2005). Fonética y fonologías españolas. Madrid. Síntesis.

Lahoz, J.M. (2012): «La enseñanza de la entonación, el ritmo y el tempo». En J. GiL (ed.). Aproximación a la enseñanza de la pronunciación en el aula de espanol. Madrid. Edinumen: 93-132.

Planas Morales, S. (en prensa): «Mecanismos de la competencia fonética del mandarín aplicados al aprendizaje de la prosodia del español». En Y. Congosto (ed.). Fonética Experimental, Educación Superior e Investigación.

Quilis, A. (2002): Tratado de fonología y fonética españolas. Madrid. Gredos.

Rico, J. (2012): «El acento y la sílaba en la clase de ELE». En J. GiL (ed.). A proximación a la enseñanza de la pronunciación en el aula de español. Madrid. Edinumen: 75-92.

Toledo, G.A. (1988): El ritmo en el español. Madrid. Gredos.

Villalba, X. (2010): El orden de las palabras en español. Madrid. Castalia. 